\title{
CRÍTICAS DE LECTORES EN LAS REDES SOCIALES LITERARIAS FRANCÓFONAS: ¿HACIA UNA POLARIZACIÓN DE LA PRESCRIPCIÓN?*
}

\author{
Louis Wiart ${ }^{\star \star}$
}

RESUMEN: Babelio es una red social de lectores dedicada a reseñas de libros y a intercambios literarios. A partir de una encuesta cuantitativa, estudiamos la distribución de reseñas de los usuarios en la red social para 1000 novelas publicadas en 2012. Mostramos en particular que la dinámica de visibilización de Babelio favorece la polarización de la atención. Por un lado, vemos un efecto "estrella" con la concentración de reseñas sobre libros que pertenecen al "star system". Por otro, observamos un efecto de "larga estela" con una democratización del acceso a la visibilidad de muchos otros novelistas que sacan partido de su presencia en línea.

PALABRAS CLAVE: Redes Sociales. Babelio. Internet. Libros Digitales.

Nacida de la web social, toda una generación de redes dedicadas al libro propone modos de utilización y sociabilidad organizados en torno a la prescripción. Al poner a disposición de los internautas un conjunto de herramientas de crítica, catalogación, interacción, exploración y documentación en torno a los libros y la lectura, estas redes desarrollan lógicas específicas de producción, distribución y evaluación de la información literaria.

Sus servicios se basan en una movilización masiva de los internautas que producen, por un proceso participativo, la mayoría de los contenidos disponibles (críticas, notas, listas, votos, comentarios, tags, etc.). Una vez visibles en línea, estos contenidos son presentados en forma agregada y jerarquizada en las páginas bibliográficas de las obras. Por otra parte, las redes sociales de lectores se apoyan en una lógica de difusión progresiva de la información: al producir un discurso sobre sus propias lecturas, los internautas se convierten en canales de comunicación, difunden a través de sus contactos las informaciones literarias y alimentan el boca a

\footnotetext{
* Traducción de Adrián Menéndez de la Cuesta.

** Université Paris 13, France. E-mail: Iwiart@hotmail.fr
} 
boca digital a su alrededor. Además, estas redes permiten una cierta personalización de los servicios a través de motores de recomendación automática que escogen los libros que estiman interesantes para los internautas a partir de la identificación de sus gustos literarios y los datos de los que disponen, pero también a través de sistemas de contactos (amigos, seguidores, etc.), lo cual implica una selección de la información por fuentes con las que existe una proximidad de intereses y afinidades.

La aparición y desarrollo de las redes sociales literarias a lo largo de la década de los 2000 hasta nuestros días ha venido acompañado por un proceso de industrialización de la prescripción literaria observable en la masificación de su uso por los internautas, la profesionalización de las iniciativas y el posicionamiento en el segmento de actividad de empresas provenientes de la industria de la cultura y la comunicación (editoriales, librerías en línea, empresas de telefonía, editores de software, start-ups, etc.). Las empresas propietarias de estas redes parten un proceso de captación y movilización de una comunidad de internautas en una perspectiva de producción comercial. La temática de la exploración y la diversidad literaria ocupa un primer plano en los discursos de estos actores mercantiles, justificando al mismo tiempo la utilidad de sus servicios.

Por sus principios de funcionamiento y las actividades que suscitan, las redes sociales de lectores poseen mecanismos de popularidad y visibilidad que le son característicos. El principal valor añadido de estas redes procede de una descentralización de la prescripción (BENHAMOU, 2014), de una capacidad para recoger, construir y poner a disposición de todos las experiencias de lectura de los internautas, como también para apoyarse en gigantescas bases de datos en línea que generan una información inédita. En muchos aspectos se diferencian de los modelos de prescripción tradicionales en los que la focalización de la atención resulta de un proceso editorial en el que el editor de contenidos ejerce un filtro previo y conserva una ínfima parte de la producción literaria que pretende abordar y destacar. Por el contrario, las redes sociales de lectores privilegian un modo de acceso a la información que se funda sobre un aumento cuantitativo de la oferta en la página web y sobre la identificación a posteriori de contenidos y recursos por el internauta (BENGHOZI, 2011).

Texto Digital, Florianópolis, Santa Catarina, Brasil, v. 12, n. 2, p. 145-160, jul./dez. 2016. ISSNe: 1807-9288. 
¿Implica esta evolución del entorno de la prescripción un cambio en la focalización de la atención de los lectores? ¿La distribución de la prescripción en línea refleja siempre las relaciones y las jerarquías del mundo tradicional? ¿Manifiesta por el contrario una apertura de acceso a la visibilidad para obras más restringidas? Mediante el estudio de caso de la página web Babelio, este artículo pretende responder a estas preguntas y aportar elementos de comprensión a la prescripción literaria en el contexto de las redes sociales de lectores.

\section{Un estudio de caso: la red Babelio}

El acceso que proponemos a esta problemática se basa en los datos relativos a la red Babelio. Fundada en 2007 por Pierre Fremaux, Guillaume Teisseire y Vassil Stefanov, Babelio es a día de hoy la red francófona más popular dedicada al libro, con más de un millón de visitantes únicos por mes a principios de 2016 según el instituto Nielsen ${ }^{\dagger}$ Concebida al principio como iniciativa amateur sin verdadera perspectiva comercial, la página web se apoya ahora en una start-up establecida en París que da empleo a media docena de personas y saca beneficios de su rendimiento en función de las visitas y la participación. Al navegar y dedicarse a diversas actividades en línea (críticas, notas, catalogación, etc.), los internautas que utilizan Babelio producen valor económico, principalmente tráfico de datos y contenidos que después se convierten en objeto de monetización. El modelo de negocio de Babelio descansa por tanto sobre una lógica de acceso gratuito para los lectores y una comercialización de servicios de cara a los profesionales del libro (publicidad, servicio de prensa, enriquecimiento de los catálogos informatizados de las bibliotecas, etc.). Fuente de enriquecimiento, el trabajo gratuito de los internautas nutre la dinámica comercial de la red cuyo atractivo crece a medida que aumenta su uso.

El volumen de críticas y evaluaciones alojadas en Babelio es muy importante y la red reivindica más de 500000 crónicas de lectores en 2014. Al ser preguntado por la

\footnotetext{
${ }^{1}$ Institut Nielsen: <http://www.nielsen.com/fr/fr.html>.

Texto Digital, Florianópolis, Santa Catarina, Brasil, v. 12, n. 2, p. 145-160, jul./dez. 2016. ISSNe: 1807-9288.
} 
distribución de prescripciones y sobre las dinámicas de visibilidad en funcionamiento en la red de la que está a cargo Pierre Frémaux responde lo siguiente:

\begin{abstract}
"No hemos realizado un estudio sobre la distribución exacta de las opiniones de los lectores. No obstante, los libros más criticados en Babelio también son automáticamente los de muy buenas ventas: en el podio están Hunger Games de Suzanne Collins, Le cercle littéraire des amateurs d'épluchures de patates de Annie Barrows y La vérité sur l'affaire Harry Québert de Joël Dicker. Pero el star system de los más comentados no es el mismo que el de los más leídos en Babelio (Le Petit Prince o L'Étranger por ejemplo) y sigue siendo asimismo diferente respecto al de las mejores ventas: la tipología de libros sobre los que se comenta es particular. Además, hay claramente un fenómeno de larga estela con 600.000 obras diferentes leídas por los miembros de Babelio, en estilos muy diversos (...)" (WIART, 2014).
\end{abstract}

El responsable de Babelio llama la atención sobre el hecho de que las prescripciones sobre la red tendrían automáticamente tendencia a concentrarse sobre las obras populares cuyo éxito comercial está asentado, mientras que un gran número de obras menos conocidas, con una larga estela, se beneficiarían igualmente de una mayor visibilidad. Desde esta perspectiva es posible suponer que las prescripciones en una red social como Babelio favorecen los dos extremos de la distribución, lo que podría en definitiva acarrear una polarización de la atención de los internautas entre el star-system y los libros para un nicho de mercado.

Nuestra intención es verificar empíricamente esta hipótesis, mediante una metodología cuantitativa que se inscribe en la línea de estudios sobre la distribución de evaluaciones en línea de bienes culturales (PASQUIER et al., 2014; PELTIER et TOURE, 2013; BASTARD et al. 2012; DELLAROCAS et al. 2010). Sobre un corpus delimitado de libros (1000 nuevas novelas publicadas en Francia entre el 28 de agosto de 2012 y el 26 de octubre de 2012), hemos recogido en abril de 2014, a partir de la base bibliográfica Electre concebida para los profesionales del libro y la edición, todas las informaciones disponibles sobre el libro en sí (título, autor, ISBN, editor, distribuidor, género, lengua original) y sobre las críticas provenientes de medios tradicionales (extractos de novelas emitidos en televisión, en la prensa escrita y en la radio), que hemos comparado con los datos extraídos de Babelio (críticas, notas, nota media). Los resultados que hemos obtenido nos ilustran sobre 
las dinámicas que gobiernan la distribución de las prescripciones en la red social de lectores.

\section{La distribución de las evaluaciones en forma de ley potencial}

Cuando una persona se inscribe en Babelio, un internauta puede publicar evaluaciones sobre cualquier libro referenciado en la base de datos. A este respecto, la selección de libros se deja libre al internauta, cuya evaluación combina una dimensión aritmética (la atribución de una nota) y/o una dimensión expresiva (la redacción de una crítica) (BEAUVISAGE et al., 2013). En el Gráfico 1 se observa que la curva de distribución estadística de las críticas de Babelio obedece a una ley de potencias: la atención de los internautas en la red social de lecturas es objeto de una repartición muy desigual, con unos pocos títulos que concentran un gran número de críticas y muchos títulos que reciben un número muy reducido. Más concretamente, el top 5 de los libros más evaluados recoge por sí solo el $32 \%$ de las críticas de la muestra y, si expandimos estos resultados al top 20 , entonces el $54 \%$ de críticas estarán incluidas.

Gráfico 1 - Distribución del número de críticas por libro en Babelio

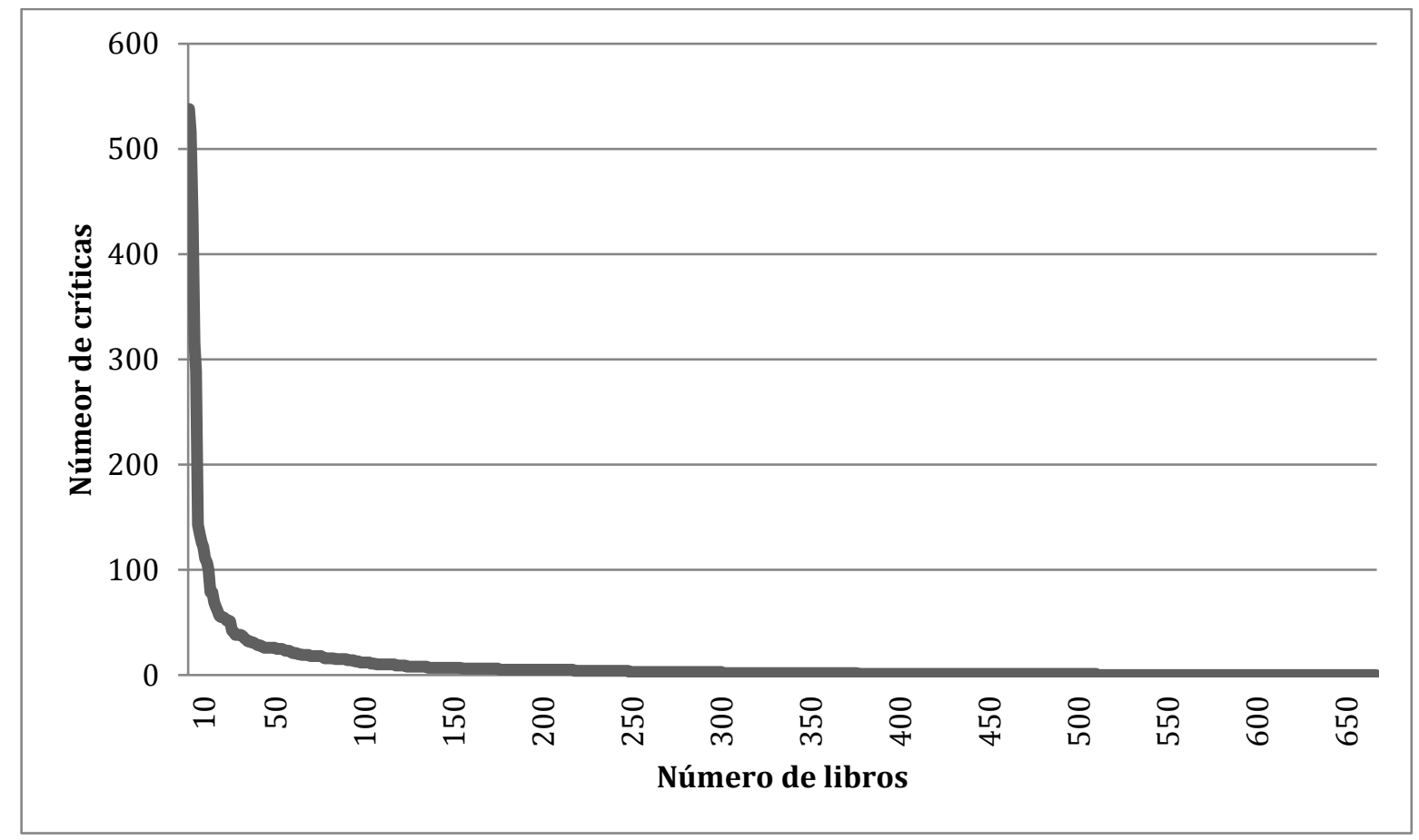


Tabla 1 - Top 20 de libros con más críticas en Babelio

\begin{tabular}{|c|c|c|c|}
\hline Título & Autor & $\begin{array}{l}\text { Número de } \\
\text { críticas }\end{array}$ & $\begin{array}{l}\% \text { de críticas } \\
\text { de la muestra }\end{array}$ \\
\hline La vérité sur l'affaire Harry Quebert & Joël Dicker & 538 & $8 \%$ \\
\hline $\begin{array}{l}\text { Le vieux qui ne voulait pas fêter son } \\
\text { anniversaire }\end{array}$ & Jonas Jonasson & 516 & $8 \%$ \\
\hline Cinquante nuances de Grey 1 & E.L. James & 437 & $7 \%$ \\
\hline Une place à prendre & J. K. Rowling & 315 & $5 \%$ \\
\hline Certaines n'avaient jamais vu la mer & Julie Otsuka & 289 & $4 \%$ \\
\hline Le trône de fer : l'intégrale & George R.R. Martin & 143 & $2 \%$ \\
\hline Ne me touche pas & Tahereh Mafi & 134 & $2 \%$ \\
\hline 14 & Jean Echenoz & 126 & $2 \%$ \\
\hline Complètement cramé ! & Gilles Legardinier & 122 & $2 \%$ \\
\hline $\begin{array}{l}\text { La lettre qui allait changer le destin } \\
\text { d'Harold Fry arriva le mardi... }\end{array}$ & Rachel Joyce & 111 & $2 \%$ \\
\hline La stratégie Ender & Orson Scott Card & 107 & $2 \%$ \\
\hline Kaïken & $\begin{array}{l}\text { Jean-Christophe } \\
\text { Grangé }\end{array}$ & 100 & $2 \%$ \\
\hline Le dernier Lapon & Olivier Truc & 79 & $1 \%$ \\
\hline Atomka & Franck Thilliez & 79 & $1 \%$ \\
\hline Troisième humanité & Bernard Werber & 69 & $1 \%$ \\
\hline A découvert & Harlan Coben & 65 & $1 \%$ \\
\hline L'hiver du monde & Ken Follett & 61 & $1 \%$ \\
\hline Sacrifices & Pierre Lemaitre & 56 & $1 \%$ \\
\hline Le cercle & Bernard Minier & 55 & $1 \%$ \\
\hline Fête fatale & William Katz & 55 & $1 \%$ \\
\hline
\end{tabular}

Para explicar esta concentración de críticas en unas cuantas obras literarias, se podría suponer que un libro recibe más evaluaciones por parte de los internautas precisamente porque es muy apreciado. La nota media del conjunto de títulos de la muestra es de $3,5 / 5$, lo que se traduce en una especie de consenso alrededor de 
una nota que se podría calificar de "bastante buena". Como se ve en el Gráfico 2, que relaciona el número de críticas obtenidas por cada novela con su nota media, la mayoría de libros de nuestra muestra recibe una nota media comprendida entre 3 y 4,5. A la vista de los datos, nada parece indicar que los libros más criticados sean también los mejor evaluados: estos figuran más bien en medio de todos los demás, en el pelotón de las evaluaciones. En otras palabras, el número de críticas recibidas por un título no parece traducirse en una satisfacción particular por parte de los lectores, sino más bien el resultado de una popularidad y una notoriedad cuyos signos más tangibles nos quedan aún por entender.

Gráfico 2 - Número de críticas recibidas en función de la nota media

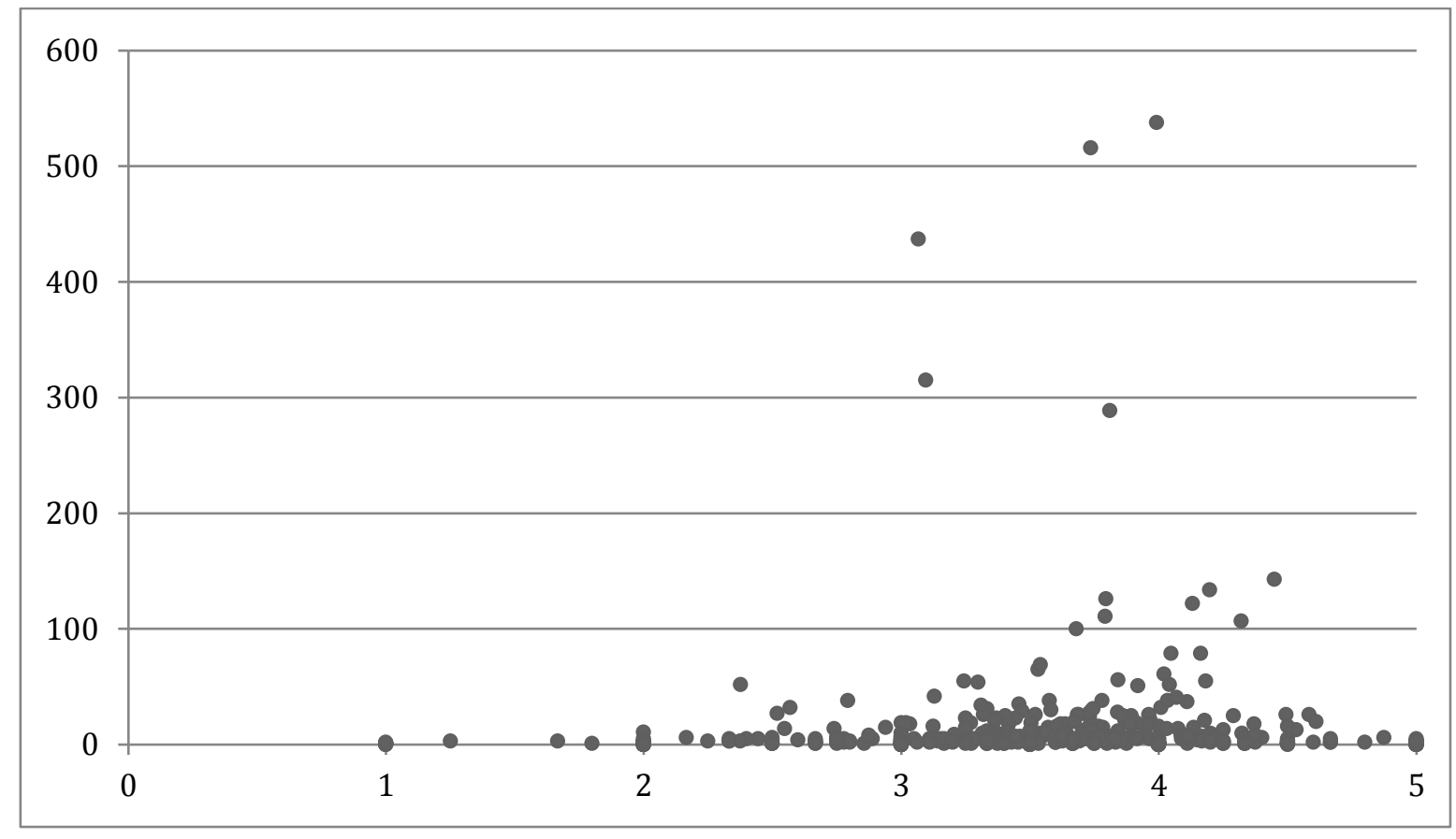

Nota: hemos desechado los libros que no habían recibido ninguna nota o crítica

\section{El peso del éxito comercial}

Más allá de esta primera constatación, es importante comparar los datos relativos a Babelio con los indicadores de éxito comercial. Con este fin hemos dividido nuestra muestra en función de los resultados de las novelas en términos de venta: 
- Las novelas superventas (vendidos entre 935000 y 50000 ejemplares) que corresponden a un efectivo de 20 títulos y al $2 \%$ de nuestra muestra;

- las novelas de venta media (vendidos entre 50000 y 2000 ejemplares), categoría constituida por 168 títulos que comportan cerca del $17 \%$ de nuestra muestra;

- las novelas para un nicho de mercado (vendidos menos de 2000 ejemplares) con un total de 809 títulos y que representan el $81 \%$ de nuestra muestra.

Como se aprecia en la Tabla 2, el número medio de notas y críticas por título crece en función del éxito comercial: las novelas superventas cuentan con 380 notas y 121 críticas de media, frente a las 53 notas y 18 críticas de las novelas de venta media y 4 notas y 1,5 críticas de las novelas-nicho. Cuanto más se vende un libro, más posibilidades tiene de recibir evaluaciones en Babelio, lo permite señalar la continuidad entre el mercado del libro y la prescripción literaria en Internet.

En general es más frecuente que un internauta añada una nota a un libro y no tanto que redacte una crítica en Babelio. De media, las novelas que componen nuestra muestra obtienen 20 notas y 6,7 críticas, lo que significa que registran 2,9 notas por cada crítica. Hay entonces una distancia importante pero bastante lógica entre las actividades de prescripción que se basan en un esfuerzo de redacción y aquellas que se limitan a un simple clic. Sin embargo esta distancia se reduce a medida que el éxito comercial de las novelas disminuye: las novelas especializadas tienen una ratio notas/críticas menos elevada $(2,7)$ que las novelas de venta media $(2,9)$, que tienen a su vez una ratio menor que las novelas superventas $(3,1)$. Aparentemente las novelas-nicho se distinguen por una mejor capacidad para traducir una actividad prescriptiva de redacción. Tras leer un libro, un internauta inscrito en Babelio puede ponerle nota o redactar la crítica (o ambas); este arbitraje se resuelve más a favor de la redacción de una crítica en los libros menos vendidos y menos evaluados. Dicho de otro modo, cuanto menos éxito comercial encuentra un libro, menos evaluaciones recibe por parte de los internautas, pero los lectores de ese libro tendrán una mayor tendencia a escribir sus propias críticas. Para ciertos lectores de novelas superventas que ya han recibido decenas, incluso centenas de críticas, se produce 
sin duda un efecto desalentador a la hora de redactar una crítica suplementaria que se añadiría a este enorme volumen.

Tabla 2 - Críticas y notas en Babelio en función del éxito comercial

\begin{tabular}{|l|l|l|l|l|l|l|}
\hline & Efectivo & Notas & Críticas & $\begin{array}{l}\text { Número } \\
\text { medio de } \\
\text { notas } \\
\text { recibidas/ } \\
\text { Título }\end{array}$ & $\begin{array}{l}\text { Número } \\
\text { medio de } \\
\text { críticas } \\
\text { recibidas/ } \\
\text { Título }\end{array}$ & $\begin{array}{l}\text { Ratio } \\
\text { Notas/ } \\
\text { Críticas }\end{array}$ \\
\hline $\begin{array}{l}\text { Novelas } \\
\text { superventas }\end{array}$ & 20 & 7600 & 2423 & 380 & 121,1 & 3,1 \\
\hline $\begin{array}{l}\text { Novelas de } \\
\text { venta media }\end{array}$ & 168 & 9016 & 3052 & 53,6 & 18,1 & 2,9 \\
\hline $\begin{array}{l}\text { Novelas } \\
\text { nicho de } \\
\text { mercado }\end{array}$ & 809 & 3345 & 1234 & 4,1 & 1,5 & 2,7 \\
\hline Total & 997 & 19961 & 6709 & 20 & 6,7 & 2,9 \\
\hline
\end{tabular}

\section{Continuidad y rupturas con respecto a los medios tradicionales}

Al comparar estos datos con los relativos a la cobertura de las novelas en los medios tradicionales, es evidente, en primer lugar, que Babelio permite una democratización del acceso a la visibilidad. Si el $49 \%$ de los títulos de la muestra no ha recibido ninguna crítica en Babelio, esta cifra se eleva hasta el $67 \%$ en la prensa, $89 \%$ en la radio y $93 \%$ en la televisión, lo que muestra que el abanico de novelas criticadas en la red social es mucho más amplio. Estos datos van en la misma línea de una dinámica favorable a la diversidad literaria en el universo digital, en el que un gran número de novelas accede a una visibilidad que le estaría habitualmente negada en los medios tradicionales. Es cierto que la situación de un órgano mediático es diferente a la de una red social como Babelio, que no tiene las mismas limitaciones en materia de línea editorial o de espacio disponible, y que se beneficia igualmente de un número mucho más elevado de contribuyentes comprometidos en las actividades prescriptivas. Si bien hay una clara apertura en el acceso a la visibilidad, esta no es total y el $33 \%$ de novelas ni siquiera son referenciadas en la base de datos de Babelio, una cifra a la que conviene añadir el $16 \%$ de novelas que son referenciadas pero que no reciben sin embargo crítica alguna. Entre estos títulos, se encuentra esencialmente la literatura francófona publicada por estructuras editoriales 
bastante restringidas o cuyas actividades se acercan a la autoedición y la edición a costa del autor.

Gráfico 3 - Reparto de las críticas por medios

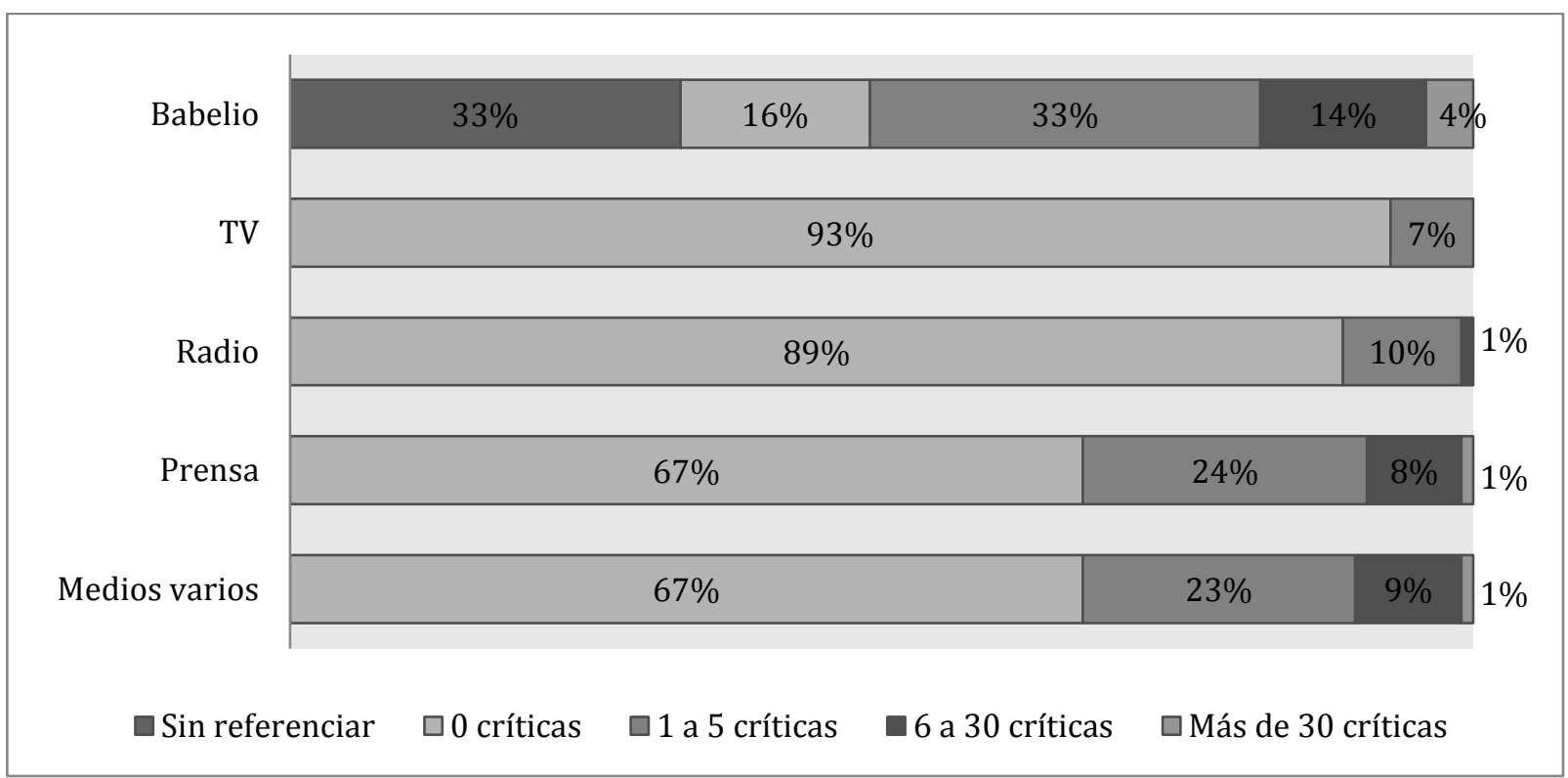

Paralelamente a esta tendencia, es posible constatar una consolidación de la atención sobre el star-system, con una concentración incrementada de las evaluaciones en línea de los best-sellers. De esta forma, las novelas que pertenecen a la categoría de superventas son más populares en Babelio que en los otros medios: los 20 títulos más vendidos reúnen el 38\% de las notas y el 36\% de críticas de la muestra de Babelio, mientras que no concentran más que el $19 \%$ de los artículos de prensa, el $22 \%$ de apariciones en la radio y el $28 \%$ en la televisión. En el otro extremo de la distribución, los libros para un nicho particular ocupan un mayor lugar en la prensa y en la radio, donde tienen un peso del 33\% para los artículos de prensa y $32 \%$ para las apariciones en radio, mientras representan el $16 \%$ de las notas y el $18 \%$ de las críticas en Babelio. Estas cifran muestran muy bien que, aunque un mayor número de libros sean criticados en Babelio, las prescripciones tienden a concentrarse prioritariamente sobre los más vendidos. 
Gráfico 4 - Cobertura mediática: Superventas, Venta media y Nicho de mercado

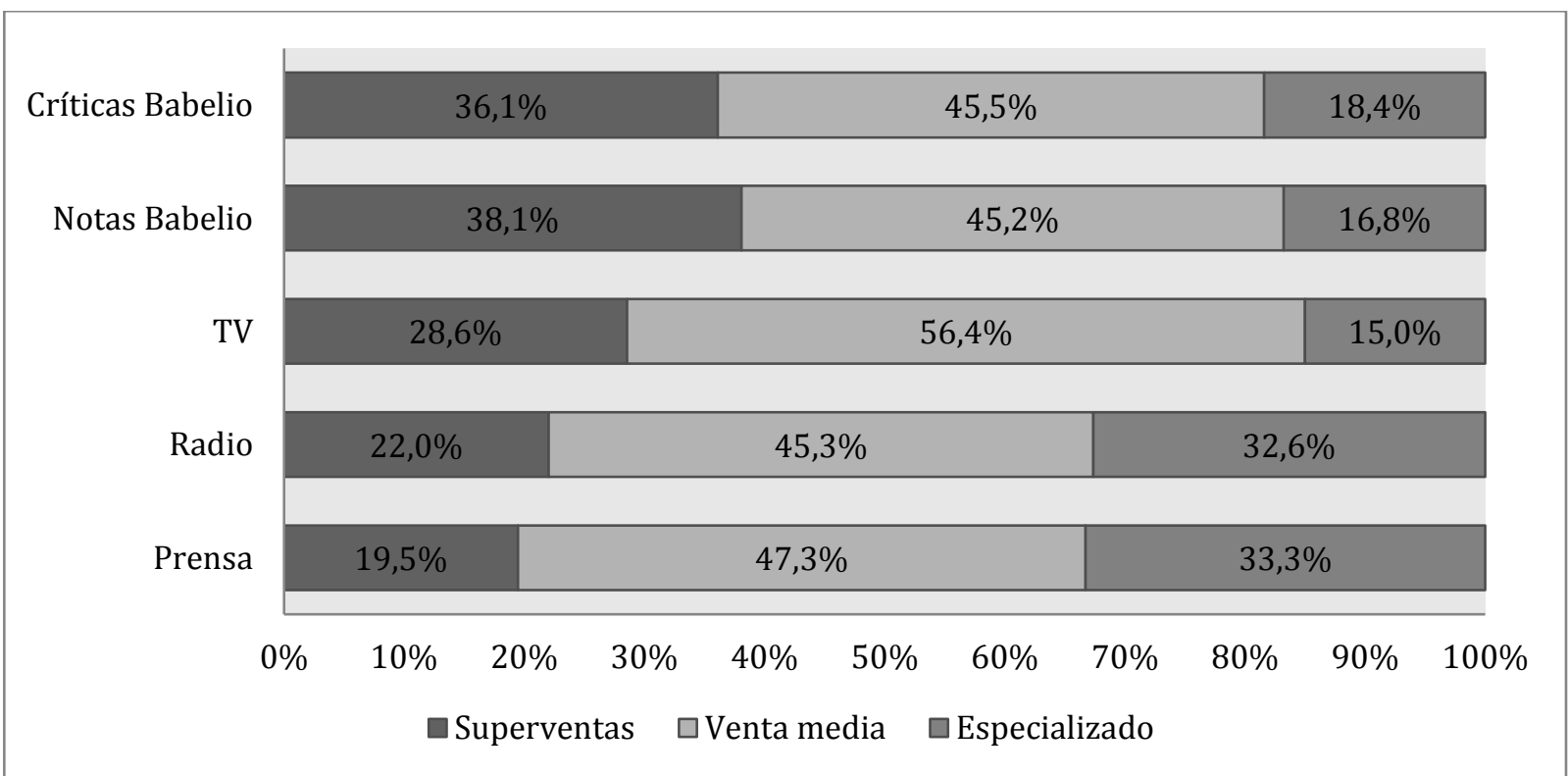

Este mecanismo de reproducción del éxito comercial debe relacionarse con una dinámica similar de reproducción del éxito mediático. El Gráfico 5 nos da claves de comprensión de este fenómeno. El número de críticas recibidas en Babelio es comparado con el rango ocupado en los medios tradicionales, mientras que al otro lado de la línea discontinua se encuentran los títulos que no se han beneficiado de aparición alguna en la televisión, radio o prensa. Por ejemplo, la novela La Vérité sur l'affaire Harry Quebert, la más popular en Babelio con más de 500 críticas de internautas, se sitúa en el extremo izquierda del gráfico, ya que se trata igualmente del título de nuestra muestra que ha sido favorecido más frecuentemente por los medios tradicionales. En su estela, Cinquante Nuances de Grey, Une Place à prendre o incluso Certaines n'avaient jamais vu la mer se caracterizan por un cúmulo de visibilidad semejante. La agrupación y la elevación de puntos en la parte izquierda del gráfico demuestran una tendencia a la reproducción en Babelio de las jerarquías de los medios tradicionales. Es más, ciertos libros como La Stratégie Ender, Le Trône de fer o Le Vieux qui ne voulait pas fêter son anniversaire se benefician de una visibilidad incrementada en Babelio, sin duda ligada al eco obtenido por sus adaptaciones audiovisuales. En cualquier caso, estos elementos nos aportan la confirmación de que la red social de lectores funciona también como 
una caja de resonancia, amplificando y reproduciendo las trayectorias de éxito de las novelas.

Gráfico 5 - Críticas en Babelio. Títulos clasificados en función de la posición ocupada en los medios tradicionales

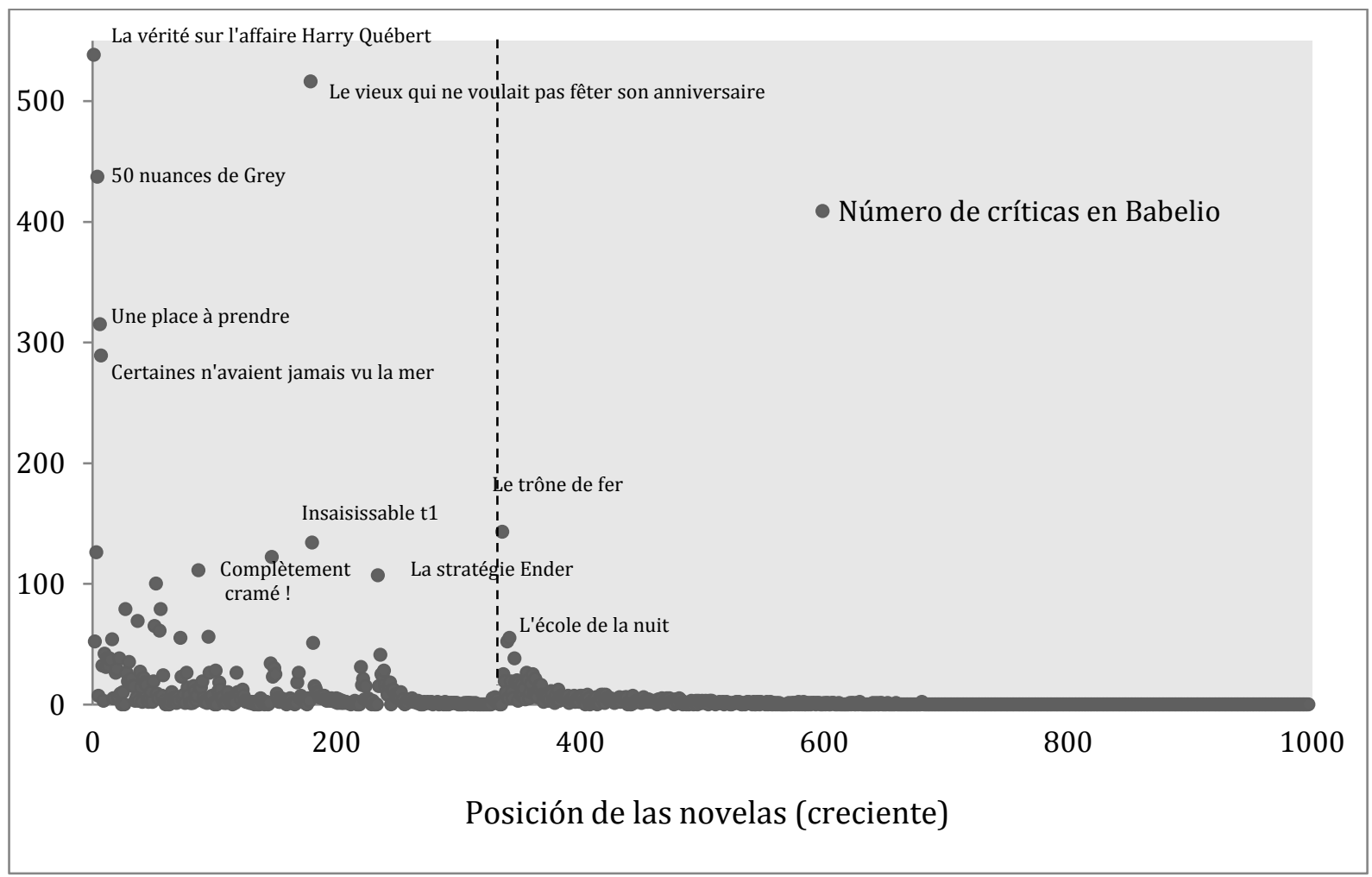

El hecho de que Babelio sea indicador de una dinámica favorable a la larga estela con una democratización del acceso a la visibilidad en beneficio de los libros para un nicho especializado el mercado, y al mismo tiempo al star-system con una concentración acrecentada de la visibilidad de los best-sellers, demuestra una tendencia a la polarización de las prescripciones en el universo digital. Este fenómeno de extensión en la distribución de las prescripciones tiende a significar que son las novelas de venta media las que se encuentran en situación más frágil por las nuevas formas del ejercicio crítico en internet. Una constatación tal nos devuelve a la dificultad que tienen los bienes culturales que se sitúan en el medio de la distribución para existir en el mundo en línea.

El análisis de la distribución de las prescripciones nos lleva a considerar otras variables susceptibles de jugar un papel significativo en la red de Babelio. Así, las 
obras pertenecientes a la literatura de género están mejor representadas en Babelio que en los medios tradicionales. La ciencia ficción, la literatura fantástica y el fantasy, así como las novelas policiacas y los thrillers, cuentan con resultados significativamente mejores. Si por ejemplo solamente el $2 \%$ de las críticas de medios están dedicadas a libros concernientes a las literaturas del imaginario, esta cifra pasa al $15 \%$ en Babelio. Estos géneros más bien abandonados por la crítica profesional se benefician marcadamente de prescripciones de los internautas, que les conceden una gran atención. Además, las novelas anglófonas tienen un peso más importante en Babelio, donde el $44 \%$ de las críticas atañen a libros traducidos del inglés frente al $27 \%$ de los medios tradicionales. Este dato no está desvinculado de la constatación planteada anteriormente, puesto que la literatura de género frecuentemente está traducida del inglés.

Tabla 3 - Reparto de críticas por género

\begin{tabular}{|l|l|l|l|}
\hline Géneros & $\%$ de libros & $\%$ de críticas Babelio & $\begin{array}{l}\% \text { de críticas } \\
\text { medios }\end{array}$ \\
\hline Literatura general & $58 \%$ & $64 \%$ & $82 \%$ \\
\hline $\begin{array}{l}\text { Ciencia ficción, fantástica y } \\
\text { fantasy }\end{array}$ & $10 \%$ & $15 \%$ & $2 \%$ \\
\hline Policiacas y thrillers & $18 \%$ & $19 \%$ & $13 \%$ \\
\hline Literatura regional & $8 \%$ & $0 \%$ & $1 \%$ \\
\hline Novelas históricas & $6 \%$ & $2 \%$ & $2 \%$ \\
\hline
\end{tabular}

Tabla 4 - Reparto de críticas por idioma

\begin{tabular}{|l|l|l|l|}
\hline Lengua de origen & \% de libros & \% de críticas Babelio & $\%$ de críticas medios \\
\hline Francófono & $68 \%$ & $42 \%$ & $58 \%$ \\
\hline Anglófono & $19 \%$ & $44 \%$ & $27 \%$ \\
\hline Resto del mundo & $13 \%$ & $14 \%$ & $15 \%$ \\
\hline
\end{tabular}

Como último enfoque, conviene abordar la cuestión de las editoriales. El millar de novelas sobre el que hemos trabajado ha sido publicado por un total de 373 editoriales, que han publicado cada una de ellas entre 1 y 48 títulos de nuestra muestra. Si la inmensa mayoría de estos editores no ha publicado más que una sola novela, un puñado de ellos es responsable de múltiples publicaciones. En la Tabla 5, 
hemos hecho una selección de veinte editoriales entre las más establecidas en el panorama literario francés. Resulta que estas veinte editoriales, por sí solas, han publicado un $23 \%$ de las novelas de la muestra, que concentran al mismo tiempo el $69 \%$ de las ventas. Del punto de vista de la prescripción, las novelas publicadas por estos editores recogen un $60 \%$ de las críticas provenientes de los medios tradicionales y un $59 \%$ de las críticas en Babelio. Mediante estas cifras se descubre de nuevo la estructura del oligopolio que caracteriza al sector de la edición, con un grupo reducido de grandes estructuras que publican lo esencial de la producción y captan una gran parte de los beneficios, frente a una multitud de pequeñas empresas de publicación generalmente menos numerosas y de participación muy débil en el mercado (BENHAMOU, 2003). Esta configuración se traduce igualmente a nivel de la prescripción en proporciones equivalentes en lo que concierne a la crítica amateur y a la crítica profesional.

Tabla 5 - Reparto de críticas por editorial

\begin{tabular}{|c|c|c|c|}
\hline Editoriales & $\begin{array}{ll}\begin{array}{l}\text { Número } \\
\text { novelas }\end{array} & \text { de } \\
\end{array}$ & $\%$ de críticas Babelio & $\%$ de críticas medios \\
\hline Presses de la Cité & 28 & $10 \%$ & $1 \%$ \\
\hline Gallimard & 27 & $3 \%$ & $13 \%$ \\
\hline Actes Sud & 18 & $2 \%$ & $2 \%$ \\
\hline Albin Michel & 15 & $5 \%$ & $5 \%$ \\
\hline Calmann-Lévy & 15 & $1 \%$ & $1 \%$ \\
\hline Grasset & 14 & $7 \%$ & $10 \%$ \\
\hline Belfond & 13 & $1 \%$ & $1 \%$ \\
\hline Seuil & 13 & $6 \%$ & $3 \%$ \\
\hline Flammarion & 11 & $2 \%$ & $5 \%$ \\
\hline Fleuve noir & 9 & $4 \%$ & $2 \%$ \\
\hline Fayard & 9 & $0 \%$ & $1 \%$ \\
\hline Lattès & 8 & $7 \%$ & $3 \%$ \\
\hline Robert Laffont & 7 & $1 \%$ & $2 \%$ \\
\hline Michel Lafon & 7 & $3 \%$ & $1 \%$ \\
\hline
\end{tabular}




\begin{tabular}{|l|l|l|l|}
\hline Rivages & 7 & $0 \%$ & $1 \%$ \\
\hline Stock & 6 & $0 \%$ & $1 \%$ \\
\hline Plon & 5 & $1 \%$ & $1 \%$ \\
\hline Mercure de France & 5 & $0 \%$ & $1 \%$ \\
\hline XO & 5 & $3 \%$ & $1 \%$ \\
\hline Minuit & 4 & $3 \%$ & $5 \%$ \\
\hline
\end{tabular}

\section{Conclusión}

Analizados a partir de métodos cuantitativos por la red de Babelio, los fenómenos de democratización y de concentración de la visibilidad que han sido descubiertos favorecen una polarización de la atención de los internautas entre el star-system y las novelas especializadas, lo que sugiere que la situación de las novelas de categoría intermedia resulta menos ventajosa en el universo digital. Varias variables intervienen en la distribución de la atención en la red social de lectores, principalmente el éxito comercial, la cobertura mediática, la pertenencia a ciertos géneros literarios, la lengua de origen del libro o incluso la editorial.

El análisis realizado a propósito de Babelio revela cómo la actividad en la red no es reducible a una larga estela de prescripciones, sino que refleja una realidad más compleja en la que se ejerce una bipolaridad fuerte entre los libros en función de su régimen económico. La desigualdad en la distribución de prescripciones señala, de un lado, un efecto de estrellato por la reproducción en Internet de las jerarquías del mundo tradicional, y, por otro, un efecto de larga estela debido a la visibilidad ofrecida a un abanico ampliado de obras literarias. En otras palabras, si esa visibilidad que procuran notas y críticas en una red social como Babelio hace accesible para la mayoría de las obras literarias, la popularidad y la notoriedad mantienen el privilegio de una pequeña élite. 


\title{
READERS' CRITICISM IN FRANCOPHONE LITERARY SOCIAL NETWORKS: TOWARDS A PRESCRIPTION OF POLARIZATION?
}

\begin{abstract}
Babelio is a social network for readers dedicated to books reviews and literary exchanges. On the basis of a quantitative survey, we studied the distribution of user reviews on the social network for 1000 novels published in 2012. We show in particular that the dynamics of visibility on Babelio favor a polarization of attention. On the one hand, we see a "star system effect" with a concentration of reviews on books belonging to the star system. On the other hand, we observe a "long tail effect" with a democratization of access to visibility for many other novels that take advantage of this online exposure.
\end{abstract}

KEYWORDS: Social Network. Babelio. Internet. Digital Books.

\section{Bibliografía}

BASTARD, Irène; BOURREAU, Marc; MAILLARD, Sisley; MOREAU, François. De la visibilité à l'attention: les musiciens sur Internet, Réseaux, París, v. 5, n.175, 2012, p.19-42.

BEAUVISAGE, Thomas; BEUSCART, Jean-Samuel; CARDON, Vincent; MELLET, Kevin; TRESPEUCH, Marie. Notes et avis des consommateurs sur le web, Les marchés à l'épreuve de l'évaluation profane, Réseaux, París, v.1, n¹77, 2013, p.131-161.

BENHAMOU, Françoise. Le livre à l'heure numérique. París: Seuil, 2014.

BENHAMOU, Françoise. L'Économie de la culture. París: La Découverte, 2003.

BENGHOZI, Pierre-Jean. Économie numérique et industrie de contenu : un nouveau paradigme pour les réseaux. Hermès, París, v.1, n59, 2011, p.31-38.

DELLAROCAS, Chrysanthos; GAO, Guodong; NARAYAN, Ritu. Are consumers more likely to contribute online reviews for hit or niche products? Journal of Management Information Systems, Armonk, NY, USA, v. 27, n. 2, 2010, p.127-157.

PASQUIER Dominique; BEAUDOUIN, Valérie; LEGON, Thomas. " Moi je lui donne 5/5 ». Paradoxes de la critique amateur en ligne. París: Presses des Mines, 2014.

PELTIER, Stéphanie; TOURE, Mamoudou. Promotion des livres sur Internet : une démocratisation de l'accès pour les auteurs de romans et de bandes dessinées ?12ème Conférence internationale de l'AIMAC, Session G2 Viral Marketing, Universidad de los Andes, Bogotá, 2013, p.935-953.

Recebido em: 01/12/2016.

Aceito em: 08/12/2016. 